\title{
Sistem Monitoring Suhu dan Gas Amonia untuk Kandang Ayam Skala Kecil
}

\author{
HERU SUPRIYONO, FAJAR SURYAWAN, RADEN MUHAMMAD AZHARI \\ BASTOMI, USMAN BIMANTORO
}

Teknik Elektro Universitas Muhammadiyah Surakarta, Indonesia

Email: Heru.supriyono@ums.ac.id

Received 29 Januari 2021 | Revised 17 Februari 2021 | Accepted 22 Maret 2021

\begin{abstract}
ABSTRAK
Suhu kandang yang tidak sesuai dengan kondisi nyaman dan adanya gas amonia dapat menyebabkan tingginya angka kematian, pertumbuhan yang tidak optimal dan menurunnya produksi telur pada ayam. Tujuan artikel ini adalah untuk menghasilkan model sistem monitoring berbasis elektronis untuk memantau suhu dan gas amonia pada kandang ayam. Model sistem monitoring yang dihasilkan dikembangkan dengan menggunakan komponen elektronika komersial meliputi sensor suhu DHT-1, sensor gas amonia MQ-135, Arduino Pro Mini, Wemos D1, Telegram, dan Blynk. Hasil pengujian pada lingkungan dalam, luar ruangan dan kandang aktual menunjukkan sistem monitoring mampu mengukur suhu pada rentang 29-33,60 ${ }^{\circ} \mathrm{C}$ dan gas amonia pada rentang 0,36-197,56 ppm secara konsisten tanpa ada perubahan hasil pengukuran yang drastis dan tiba-tiba. Sistem yang dihasilkan ini berpotensi untuk diuji pada skala yang luas dan dilakukan uji standar pengukuran.
\end{abstract}

Kata kunci: pemantau suhu, pemantau gas amonia, pemantau kandang ayam, sistem berbasis mikrokontroler

\begin{abstract}
The temperature which is not suitable and the presence of ammonia gas can cause high mortality, suboptimal growth and decreased egg production of chickens. The purpose of this publication is to produce an electronic based monitoring system model for monitoring temperature and ammonia gas in chicken coops. The model was developed using DHT-1 sensor, MQ-135 sensor, Arduino Pro Mini, Wemos D1, Telegram, and Blynk applications. The test results in indoor, outdoor, and actual chicken coop environments showed that the monitoring system was able to measure temperature, i.e. $29-33.60{ }^{\circ} \mathrm{C}$ and ammonia gas, i.e. 0.36-197.56 ppm consistently without any drastic and sudden changes in measurement results. The obtained system is potential to be tested in larger scale and measurement standard.
\end{abstract}

Keywords: temperature monitoring, Ammonia gas monitoring, chicken coop monitoring, microcontroller based system 


\section{PENDAHULUAN}

Ayam pada peternakan ayam membutuhkan perlakuan yang baik sehingga akan dapat tumbuh dengan sehat sehingga akan menghasilkan berat badan yang optimal serta karkas yang baik untuk ayam pedaging atau menghasilkan telur yang optimal untuk ayam petelur. Salah satu faktor penentu pertumbuhan ayam dan produksi telur ayam adalah faktor suhu kandang (Triawan, dkk, 2013) dimana untuk kawasan Indonesia yang merupakan daerah tropis maka kandang untuk ayam sebaiknya dijaga dalam rentang di bawah $30^{\circ} \mathrm{C}$.

Karena pentingnya kondisi suhu pada kandang maka besaran ini harus dipantau secara kontinu. Data suhu pada kandang ayam ini digunakan sebagai dasar pertimbangan peternak atau pengelola peternakan ayam untuk mengambil tindakan agar suhu kandang ayam dapat dijaga secara konstan pada rentang yang nyaman untuk ayam. Pemantauan suhu dengan hanya mengandalkan perkiraan oleh orang cenderung kurang tepat karena tidak berdasarkan data kuantitatif. Pemantauan suhu dengan berdasar alat ukur dan mencatatnya secara manual akan membutuhkan orang yang khusus mengerjakan tugas pembacaan suhu dan mencatat datanya serta juga memakan waktu yang cukup lama.

Ayam membutuhkan suhu dalam rentang tertentu untuk tumbuh dan hidup secara optimal (Alimuddin, dkk, 2012). Apabila ayam berada pada lingkungan dengan suhu di bawah atau di atas suhu nyamannya maka ayam akan mengalami stres yang dapat menyebabkan ayam mengalami perubahan fisiologis dan hormonal. Kondisi ini dapat mempengaruhi tingkah laku, terganggunya fungsi alat pernafasan dan jantung. Efek selanjutnya adalah menurunnya asupan makanan dan konversi makanan ke daging atau produktivitas telur yang pada akhirnya merugikan peternak (Tamzil, 2014).

Penerapan sistem berbasis elektronik untuk kandang ayam cukup menarik perhatian peneliti terkait berbagai proses yang terjadi pada peternakan ayam. Sekelompok peneliti menguraikan hasil penelitiannya tentang pengendalian pemberian minum dan makan pada kandang ayam secara jarak jauh (Muta'affif, dkk, 2017). Kelemahannya adalah sistem ini masih dalam bentuk model miniatur dan belum sampai pada pengujian pada kandang yang sebenarnya. Kelompok peneliti lain membuat model pengendalian suhu pada model kandang ayam yaitu apabila hasil pengukuran suhu kandang oleh sistem elektronik tinggi maka sistem akan secara otomatis menghidupkan pompa air yang disemprotkan pada kandang sehingga dapat menurunkan suhu kandang selama waktu yang ditentukan kemudian mematikan pompa air secara otomatis (Budianto, dkk, 2017). Sistem masih dalam bentuk model miniatur. Apabila model sistem yang dikembangkan ini diterapkan dalam kondisi kandang aktual maka membutuhkan infrastruktur sumber air, penampung dan sumber daya listrik yang besar yang cocok untuk peternakan skala menengah atau besar. Hasil penelitian selanjutnya, sistem elektronik berbasis mikrokontroler diterapkan untuk mengendalikan suhu kandang. Apabila suhu kandang berada pada nilai di atas kondisi nyamannya maka sistem elektronik akan secara otomatis menyalakan kipas yang dipasang dalam kandang untuk menurunkan suhu. Hasil pengujian pada kandang dengan kapasitas 600 ekor ayam selama dua minggu menunjukkan bahwa penerapan sistem elektronis ini mampu menurunkan angka kematian ayam dari 64 ekor pada kandang biasa menjadi 31 ekor pada kandang yang menggunakan sistem elektronik (Putra, dkk ,2018).

Selain suhu kandang, faktor lain yang sangat mempengaruhi kesehatan ayam dan juga orang yang bekerja didalalamnya adalah kualitas udara kandang terutama gas amonia

(Maliselo \& Nkonde, 2015) (Kilic \& Yaslioglu, 2014). Kotoran ayam yang tercampur dengan alas kandang (litter) lalu mengalami proses fermentasi akan menghasilkan gas 
amonia. Semakin banyak ayam akan menghasilkan semakin banyak kotoran ayam maka akan semakin banyak pula gas amonia yang dihasilkan. Kadar gas amonia dinyatakan dalam satuan

Part per million (ppm). Berdasarkan hasil penelitian dapat diketahui bahwa tingginya kadar gas amonia pada kandang akan berpengaruh pada ketahanan ayam terhadap penyakit yang dapat berujung pada turunnya produktifitas termasuk angka kematian yang tinggi (Renata, dkk, 2018).

Sistem elektronik berbasis mikrokontroler dapat diimplementasikan untuk melakukan pendeteksian dan pencatatan adanya gas tertentu di alam secara otomatis untuk menggantikan pendeteksian dan pencatatan secara manual oleh orang seperti untuk deteksi gas yang mudah terbakar. Hasil penelitian menunjukkan bahwa sistem elektronis dapat mendeteksi adanya gas dengan presisi dan mencatatnya dalam perangkat penyimpan dalam bentuk file lebih cepat dibandingkan dengan proses manual (Supriyono \& Hadi, 2017). Penelitian lainnnya adalah pengembangan sistem berbasis komputer untuk memantau kadar gas amonia dan metana pada sebuah model kandang ayam. Hasil penelitian menunjukkan bahwa teknologi jaringan komputer memungkinkan pengelola kandang untuk memantau kadar amonia dan metana pada kandang secara jarak jauh dan berpotensi untuk dikembangkan lebih lanjut untuk diaplikasikan pada kandang ayam yang sebenarnya. Gas amonia pada suatu ruangan dapat hilang terbawa aliran angin (Arifin, dkk, 2018) (Heriawan, dkk, 2013) mempublikasikan hasil penelitiannya tentang perancangan model alat untuk mendeteksi adanya gas amonia dan menghilangkannya dengan cara menghidupkan kipas angin sebagai sumber aliran angin. Alat diuji pada sebuah toples plastik yang memodelkan ruangan tertutup yang di dalamnya diberi gas amonia dengan kadar tertentu, jika sistem elektronis mendeteksi kadar amonia melebihi nilai yang sudah ditentukan maka sistem elektronis akan menghidupkan kipas dan apabila kadar amonia sudah di bawah ambang batas maka sistem elektronis akan mematikan kipas secara otomatis.

Sistem berbasis elektronika yang terdiri dari sensor terutama untuk monitoring suhu dan kualitas udara pada kandang ayam dinilai berpotensi besar diterapkan pada industri peternakan ayam untuk optimisasi sistem pengelolaan (Corkery, dkk, 2013). Teknologi Internet of Things (IoT) juga diusulkan untuk diimplementasikan pada pengelolaan peternakan ayam untuk meningkatkan kesehatan ayam dan kualitas daging (EsnaolaGonzales, dkk, 2020).

Berdasarkan uraian di atas, dengan mempertimbangkan bahwa suhu dan kadar gas amonia sangat penting dalam pertumbuhan dan kesehatan ayam, maka kedua variabel itu sangat perlu untuk selalu di-monitor secara otomatis dengan menggunakan sistem berbasis elektronik. Penelitian tentang monitoring suhu dan kadar gas amonia pada lingkungan kandang ayam sesungguhnya masih jarang dipublikasikan oleh peneliti sebelumnya. Dibandingkan dengan hasil penelitian yang dipublikasikan oleh peneliti sebelumnya yang masih dalam bentuk model miniatur, sistem yang dikembangkan dalam artikel ini dirancang dengan tujuan untuk diterapkan pada kondisi kandang ayam sesungguhnya. Sistem dirancang untuk kandang ayam rakyat skala mikro dan kecil yang belum banyak tersentuh teknologi. Rumusan permasalahan pada publikasi ini adalah bagaimana mengimplementasikan sistem elektronis berbasis mikrokontroler untuk melakukan pemantauan parameter lingkungan kandang ayam yang utama yaitu suhu dan kadar gas amonia. Tujuan publikasi ini adalah untuk menghasilkan suatu model sistem elektronis untuk pemantauan suhu dan kadar gas amonia yang dapat diimplementasikan pada kandang ayam. Suhu dan kadar gas amonia dapat dipantau dari jarak jauh dengan menggunakan 
telepon pintar Android sehingga dapat digunakan sebagai dasar untuk analisis dan pengambilan keputusan.

\section{METODE PENELITIAN}

Secara umum ada dua jenis kandang ayam yaitu kandang ayam sistem terbuka dan kandang ayam sistem tertutup. Kandang ayam sistem terbuka adalah kandang ayam dimana dinding kandang dibuat ada celah atau bagian seperti jendela atau penutup dinding dari kain atau terpal yang dapat dibuka dan ditutup sewaktu-waktu untuk menjaga suhu kandang pada suhu nyaman. Bagian pada dinding ini atau penutup akan dibuka pada siang hari agar udara dari luar masuk dan akan ditutup pada sore hari untuk menjaga agar suhu dalam kandang tetap hangat.

\subsection{Arsitektur Sistem}

Sistem elektronis yang diusulkan ini akan mengambil studi kasus untuk kandang sistem terbuka yang banyak digunakan oleh peternakan ayam rakyat yang kebanyakan adalah peternak skala mikro dan kecil di daerah pedesaan. Sistem pemantauan yang dikembangkan dapat digunakan oleh pengelola kandang untuk memantau apakah suhu yang ada dalam kandang sudah sesuai, terlalu panas atau terlalu dingin. Selain itu, sistem yang diusulkan dapat digunakan untuk me-monitor kadar gas amonia di kandang. Setelah mendapatkan data-data ini kemudian pengelola kandang akan mengambil tindakan yang tepat agar kondisi kandang ayam dapat dijaga pada kondisi nyaman untuk ayam. Sistem yang dikembangkan mengadopsi teknologi Internet of Things (IoT). Keuntungan utama yang diperoleh pada implementasi IoT untuk monitoring variabel di alam adalah memungkinkan variabel dapat diamati dari jarak jauh secara kontinu dan dalam waktu nyata (Logan, dkk, 2019). Arsitektur sistem elektronis yang diusulkan secara umum dapat dilihat pada Gambar 1.

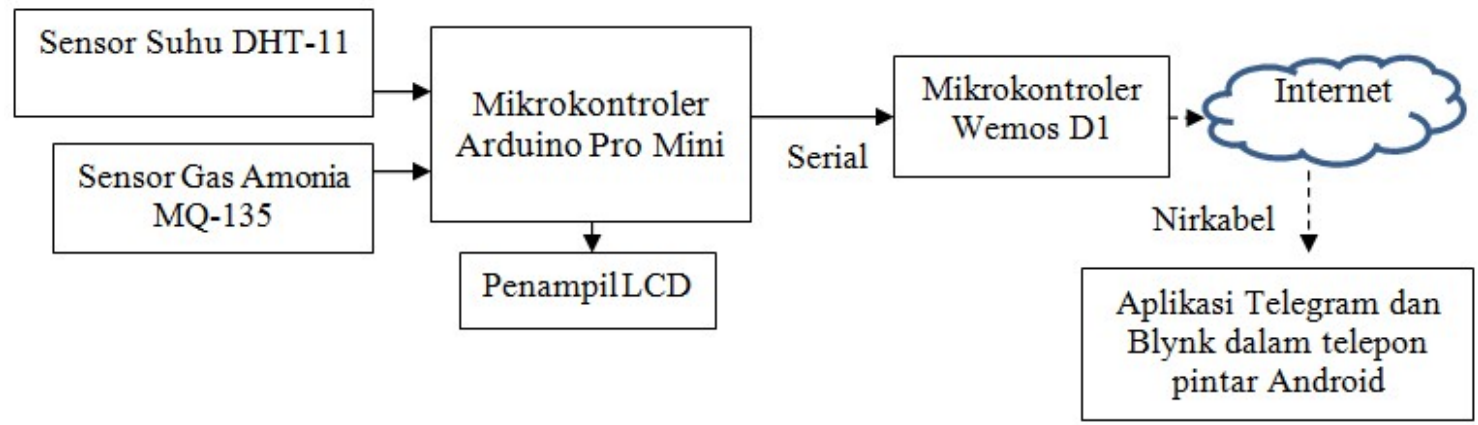

\section{Gambar 1. Blok Diagram yang Menunjukkan Arsitektur Fungsional Secara Keseluruhan Sistem Elektronis yang Dikembangkan}

Sensor suhu dan sensor gas amonia digunakan untuk mendeteksi dan mengubah suhu dan kandungan gas amonia menjadi sinyal elektronis yang kemudian diolah oleh sistem mikrokontroler yaitu Arduino Pro Mini. Sensor gas amonia yang digunakan adalah sensor komersial MQ-135 berbeda dengan sistem monitoring yang dilaporkan oleh peneliti lain yang menggunakan sensor MQ-137 (Vishesh, dkk, 2016). Besarnya suhu dan kadar gas amonia kemudian ditampilkan pada penampil Liquid Crystal Display (LCD) dan dikirimkan ke mikrokontroler Wemos D1 untuk selanjutnya dikirimkan ke telepon genggam pengelola kandang melalui program aplikasi Telegram dan Blynk. Aplikasi Telegram dan Blynk dipilih karena mempunyai unjuk kerja yang baik ketika diaplikasikan untuk notifikasi dalam sistem IoT seperti yang juga diaplikasikan untuk sistem keamanan rumah (Kurniawan, dkk, 
2018) (Hidayanti, 2020). Sistem elektronis yang dikembangkan juga dilengkapi dengan fitur notifikasi pada aplikasi Telegram untuk memberitahukan apabila suhu atau kadar gas amonia pada kandang melebihi ambang batas yang sudah ditentukan. Jika dibandingkan dengan penggunaan kombinasi antara web dan notifikasi dengan menggunakan pesan pendek Short Message Services (SMS) seperti yang digunakan pada penelitian (Budiarto, dkk, 2020), penggunaan aplikasi Telegram dan Blynk lebih sederhana dalam pengoperasiannya karena hanya membutuhkan data internet saja tanpa perlu tambahan biaya pulsa untuk SMS.

\subsection{Perancangan Perangkat Keras}

Arsitektur sistem pada Gambar 1 kemudian diwujudkan dalam rangkaian elektronika yang dapat dilihat pada Gambar 2. Sensor gas amonia yang digunakan yaitu MQ-135 akan menghasilkan keluaran berupa sinyal analog yang kemudian dikirimkan ke port A0 mikrokontroler Arduino Pro Mini untuk selanjutnya diolah (jalur warna hijau). Sensor suhu yang digunakan yaitu DHT-11 mempunyai keluaran data digital yang kemudian dikirimkan ke port D2 mikrokontroler Arduino Pro Mini (jalur warna abu-abu). Data temperatur dan gas amonia hasil olahan mikrokontroler Arduino Pro Mini kemudian dikirimkan ke mikrokotroler Wemos D1 untuk selanjutnya dikirimkan ke telepon pintar Android menggunakan aplikasi Telegram dan Blynk. Semua komponen mendapatkan daya dari baterai yaitu VCC yang ditunjukkan pada jalur warna merah sedangkan jalur ground (GND) ditunjukkan pada jalur warna hitam.

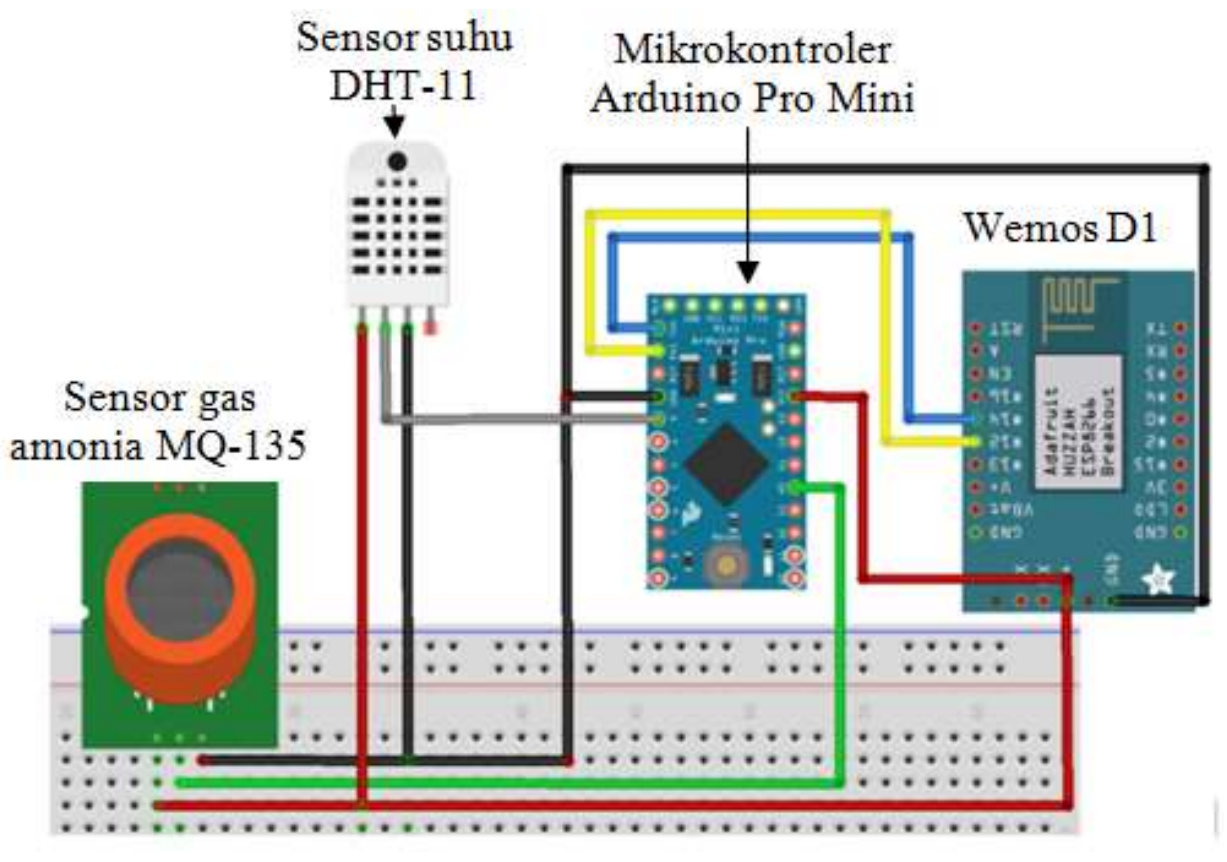

Gambar 2. Rangkaian Komponen Perangkat Keras Sistem Monitoring yang Diusulkan

\subsection{Perancangan Perangkat Lunak}

Untuk dapat bekerja mengolah sinyal maka diperlukan perangkat lunak atau program yang dikembangkan untuk mikrokontroler Arduino Pro Mini dan Wemos D1. Proses komputasi pada mikrokontroler secara keseluruhan dinyatakan dalam diagram alir yang dapat dilihat pada Gambar 3. Tahapan komputasi dimulai dengan melakukan persiapan yaitu inisialisasi sensor yang digunakan yaitu MQ-135 dan DHT-11. Kemudian dilakukan proses kalibrasi pada sensor yaitu antara keluaran sensor dan rentang nilai yang diterima oleh mikrokontroler 
Arduino Pro Mini. Setelah mendapatkan data pembacaan sensor, mikrokontroler Arduino Pro Mini melakukan komputasi besarnya suhu dan gas amonia yang terbaca oleh sensor dan kemudian menampilkannya pada penampil LCD dan mengirimkannya ke mikrokontroler Wemos D1. Komputasi pada mikrokontroler Wemos D1 dimulai dengan proses penyambungan Wemos D1 dengan jaringan wifi yang tersedia. Penggunaan jaringan komputer dan internet berbasis nirkabel dengan wifi banyak digunakan dalam pembangunan monitoring suatu variabel jarak jauh seperti yang juga digunakan dalam pemantauan konsumsi energi listrik jarak jauh (Santoso, dkk, 2018). Setelah berhasil tersambung dengan jaringan wifi yang ada maka kemudian Wemos D1 melakukan parsing data suhu dan level gas amonia untuk dikirimkan ke aplikasi Telegram dan Blynk sehingga dapat ditampilkan pada telepon pintar Android. Perangkat lunak atau program pada mikrokontroler dibuat dengan menggunakan Arduino Integrated Development Environment(IDE).
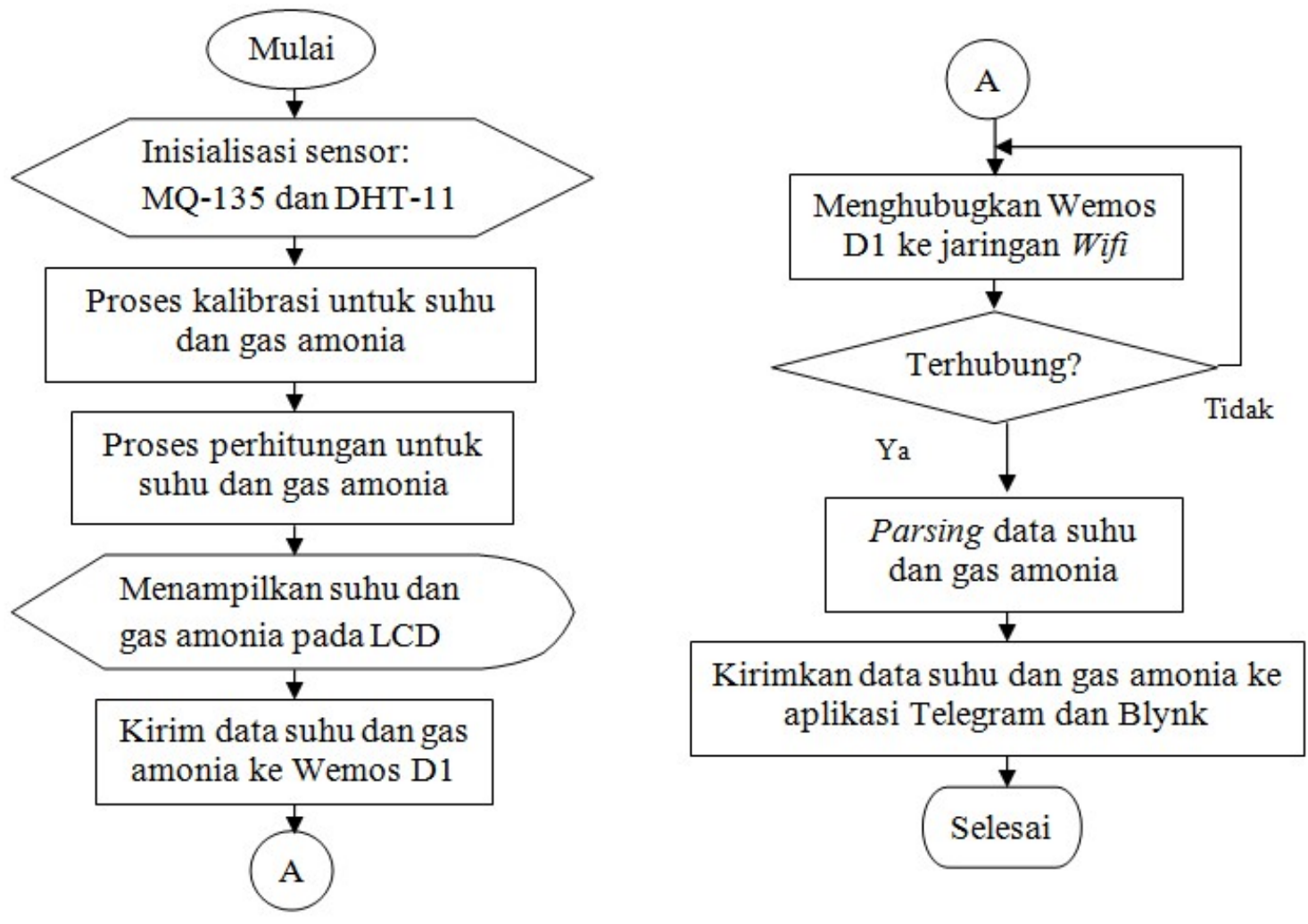

\section{Gambar 3. Diagram Alir yang Menunjukkan Proses Komputasi Secara Keseluruhan}

\subsection{Rancangan Pengujian}

Sistem yang dikembangkan diuji pada dua pengujian yaitu pengujian skala laboratorium (di dalam dan di luar ruangan) dan pengujian pada lingkungan kandang ayam aktual. Pada pengujian pada skala laboratorium dengan kondisi di dalam ruangan, sistem yang dikembangkan dan sumber gas amonia ditempatkan di dalam kaleng/ember plastik yang dibalik. Kaleng/ember plastik yang digunakan mempunyai diameter $15 \mathrm{~cm}$ dan ketinggian 17 $\mathrm{cm}$ sedangkan pada pengujian di luar ruangan baik sistem yang dikembangkan maupun sumber gas amonia ditempatkan dalam udara terbuka dalam sebuah ruangan ukuran $7 \mathrm{~m} \mathrm{x}$ $8 \mathrm{~m}$. Pada pengujian di lapangan, sistem monitoring diuji pada lingkungan kandang ayam rakyat skala mikro dengan ukuran 2,5 m (panjang) x 1,5 m (lebar) x 1,2 m (tinggi). 


\section{HASIL DAN PEMBAHASAN}

\subsection{Model Sistem Monitoring yang Dihasilkan}

Semua rangkaian perangkat keras pada sistem monitoring yang dihasilkan ditempatkan ke dalam kotak dengan ukuran $105 \mathrm{~mm}$ (panjang) x $105 \mathrm{~mm}$ (lebar) x $60 \mathrm{~mm}$ (tinggi) untuk melindungi dari goncangan, percikan air dan tumbukan. Pada artikel ini, kotak terbuat dari kayu yaitu papan tripleks. Dengan bahan kotak tripleks yang kecil, sistem monitoring mempunyai ukuran dan bobot yang ringan untuk ditempatkan dimana saja pada bagian kandang. Sensor suhu DHT-11, gas monia MQ-135 dan penampil LCD ditempatkan pada permukaan atas kotak untuk memudahkan pendeteksian suhu dan gas serta untuk melihat tampilan hasilnya. Tampilan aktual kotak sistem monitoring yang dihasilkan dapat dilihat pada Gambar 4.

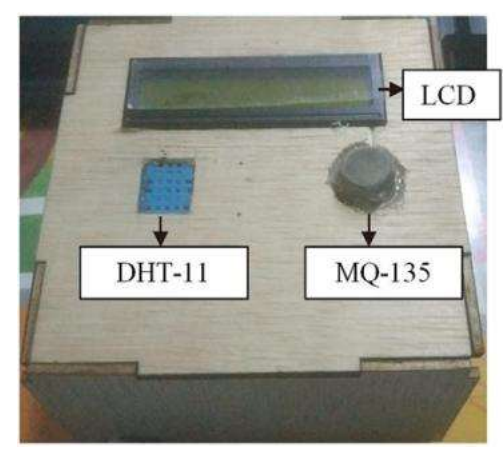

\section{Gambar 4. Tampilan Sistem Monitoring yang Dihasilkan}

\subsection{Pengujian Komunikasi Data Serial}

Pengujian komunikasi data serial diperlukan untuk mengetahui apakah data pengukuran suhu dan kadar gas amonia hasil olahan mikrokontroler Arduino Pro Mini dapat dikirimkan ke mikrokontroler Wemos D1. Pengujian ini dilakukan dengan me-monitor proses transfer data dari mikrokotroler Arduino Pro Mini ke Wemos D1 menggunakan komputer yang hasil tampilannya dapat dilihat pada Gambar 5.

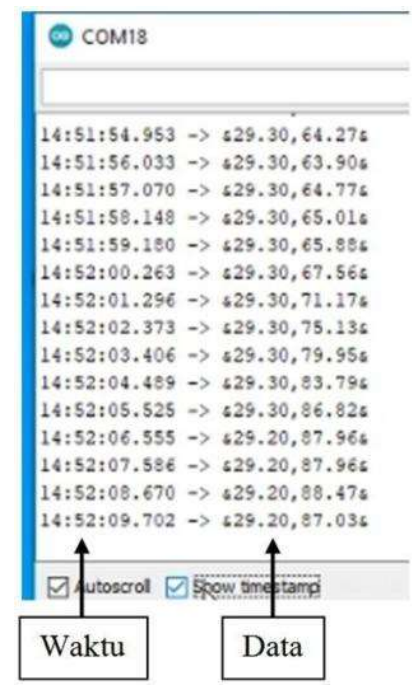

Gambar 5. Hasil Pengujian Komunikasi Data Serial dari Mikrokontroler Arduino Pro Mini ke Mikrokontroler Wemos D1 
Dari hasil pengujian dapat dilihat bahwa data dari Mikrokontroler Arduino Pro Mini dapat dikirimkan dengan lancar ke mikrokontroler Wemos D1. Data yang dikirimkan meliputi waktu pengiriman data (jam, menit, detik) dan data suhu dan kadar gas amonia yang terukur.

\subsection{Pengujian Skala Laboratorium pada Lingkungan Dalam Ruangan}

Untuk mengetahui unjuk kerja sistem monitoring yang dikembangkan, sistem diuji dalam skala laboratorium dan pada lingkungan kandang ayam aktual. Untuk pengujian pada skala laboratorium, sistem monitoing diuji pada lingkungan dalam ruangan dan luar ruangan. Untuk pengujian dalam skala laboratorium ini, larutan amonia dengan kadar 30\% (dapat dilihat pada Gambar 6) digunakan sebagai sumber gas amonia untuk memodelkan kotoran ayam yang menghasilkan gas amonia.
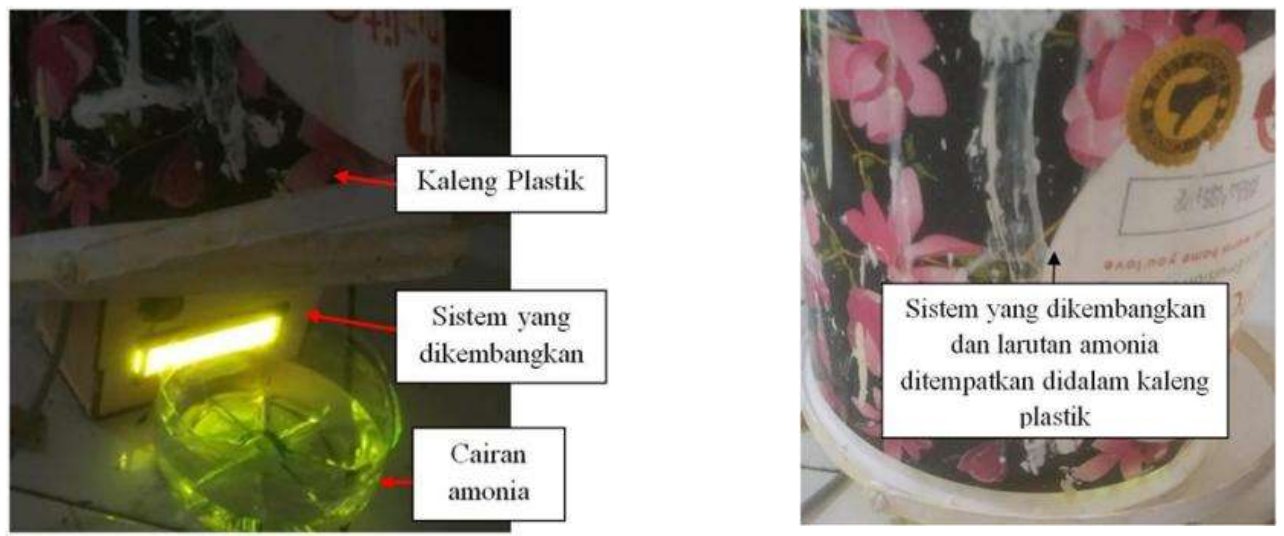

\section{Gambar 6. Susunan Eksperimen Percobaan Pengujian Skala Laboratorium pada Lingkungan Dalam Ruangan}

Proses pengujian dalam skala laboratorium pada lingkungan dalam ruangan dapat dijelaskan sebagai berikut. Pertama-tama, larutan amonia ditempatkan dalam sebuah wadah kemudian diletakkan di depan kotak sistem monitoring yang dikembangkan. Kemudian, alat dan larutan amonia ditempatkan dalam ruang tertutup yaitu dimasukkan ke dalam kaleng/ember plastik yang dibalik seperti yang dapat dilihat pada Gambar 6. Dengan susunan seperti ini, gas amonia akan tetap di dalam ruang ember plastik yang terbalik karena udara hanya akan dapat keluar masuk melalui celah di bawah kaleng/ember plastik. Jaringan wifi disediakan melalui fasilitas hotspot pada telepon pintar untuk fasilitas koneksi sistem monitoring yang dikembangkan sehingga dapat mengirimkan datanya ke aplikasi Telegram dan Blynk. Eksperimen dilakukan pada siang hari selama 30 menit. Lama waktu 30 menit dipilih karena dinilai sudah cukup lama sehingga kinerja sistem monitoring dalam rentang waktu ini sudah dapat mewakili kinerja sistem apabila digunakan sehari-hari atau sepanjang waktu.

Data hasil pengukuran suhu dan kadar gas amonia dapat dibaca pada perangkat bergerak/smartphone melalui aplikasi Telegram dan Blynk seperti yang dapat dilihat pada Gambar 7. Sebagai sampel, data pengukuran kemudian dicatat setiap menit yang ditampilkan pada Tabel 1 . Hasil pengukuran pada Tabel 1 menunjukkan alat mampu mengukur suhu yaitu antara $29,10-29,90{ }^{\circ} \mathrm{C}$ dan kadar gas amonia yaitu antara 24,12197,56 ppm dengan stabil untuk kondisi yang tidak berubah. Namun, dalam eksperimen dapat diketahui bahwa ada beberapa hasil pengukuran kadar gas amonia yang selisihnya agak banyak yaitu (1) 197,56 ppm, (2) 128,24 ppm, dan (3) 105,14 ppm yang terjadi ketika ada angin yang berhembus pada ember yang terbalik dimana larutan amonia dan sistem monitoring ditempatkan. 


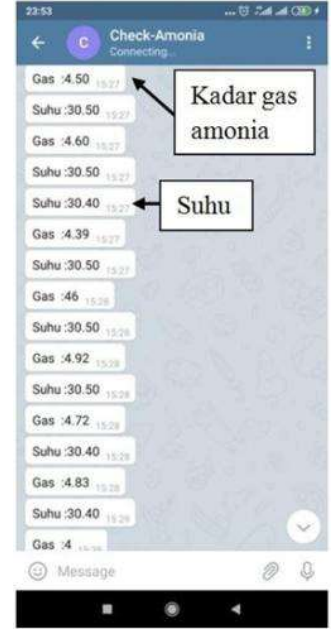

a. Tampilan pada aplikasi Telegram

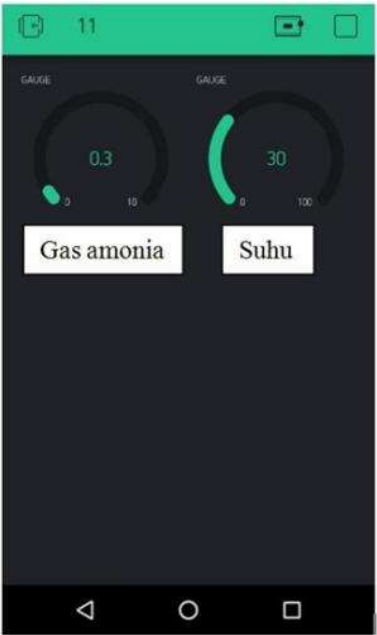

b. Tampilan pada aplikasi Blynk

Gambar 7. Tampilan Hasil Pengukuran Suhu dan Kadar Gas Amonia pada Perangkat Bergerak dengan Aplikasi Telegram dan Blynk

Tabel 1. Hasil Pengujian Sistem Monitoring yang dihasilkan pada Lingkungan dalam Ruangan

\begin{tabular}{|c|c|c|c|}
\hline Menit ke- & Kadar Gas Ammonia (ppm) & Suhu $\left({ }^{\circ} C\right)$ & Waktu Pengujian (WIB) \\
\hline 1 & 26,50 & 29,70 & $14: 44: 00$ \\
\hline 2 & 28,62 & 29,90 & $14: 45: 00$ \\
\hline 3 & 31,44 & 29,70 & $14: 46: 00$ \\
\hline 4 & 66,67 & 29,80 & $14: 47: 00$ \\
\hline 5 & 105,14 & 29,90 & $14: 48: 00$ \\
\hline 6 & 58,52 & 29,70 & $14: 49: 00$ \\
\hline 7 & 77,10 & 29,50 & $14: 50: 00$ \\
\hline 8 & 35,54 & 29,40 & $14: 51: 00$ \\
\hline 9 & 67,56 & 29,30 & $14: 52: 00$ \\
\hline 10 & 77,08 & 29,60 & 14:53:00 \\
\hline 11 & 66,60 & 29,40 & $14: 54: 00$ \\
\hline 12 & 82,12 & 29,40 & $14: 55: 00$ \\
\hline 13 & 60,14 & 29,10 & $14: 56: 00$ \\
\hline 14 & 78,06 & 29,70 & $14: 57: 00$ \\
\hline 15 & 65,76 & 29,70 & $14: 58: 00$ \\
\hline 16 & 128,24 & 29,70 & 14:59:00 \\
\hline 17 & 76,95 & 29,40 & $15: 00: 00$ \\
\hline 18 & 74,36 & 29,40 & $15: 01: 00$ \\
\hline 19 & 197,56 & 29,30 & $15: 02: 00$ \\
\hline 20 & 39,99 & 29,30 & $15: 03: 00$ \\
\hline 21 & 93,41 & 29,40 & $15: 04: 00$ \\
\hline 22 & 50,11 & 29,40 & $15: 05: 00$ \\
\hline 23 & 18,37 & 29,20 & $15: 06: 00$ \\
\hline 24 & 27,11 & 29,40 & $15: 07: 00$ \\
\hline 25 & 24,12 & 29,30 & 15:08:00 \\
\hline 26 & 41,46 & 29,70 & $15: 09: 00$ \\
\hline 27 & 31,24 & 29,90 & $15: 10: 00$ \\
\hline 28 & 36,45 & 29,60 & $15: 11: 00$ \\
\hline 29 & 46,91 & 29,40 & $15: 12: 00$ \\
\hline 30 & 33,66 & 29,50 & $15: 13: 00$ \\
\hline
\end{tabular}




\subsection{Pengujian Skala Laboratorium pada Lingkungan Luar Ruangan}

Pengujian luar ruangan dilakukan dengan tahapan yang hampir sama dengan pengujian pada lingkungan dalam ruangan namun larutan amonia dan sistem monitoring yang dikembangkan ditempatkan pada ruangan terbuka seperti yang dapat dilihat pada Gambar 8. Dapat dilihat pada kondisi ini terdapat aliran udara bebas dan angin. Suhu lingkungan dan kadar gas amonia yang terukur dilihat menggunakan aplikasi Telegram dan Blynk pada telepon pintar Android hampir sama dengan yang ditunjukkan pada Gambar 7. Eksperimen dilakukan pada siang hari selama 16 menit dan data yang dicatat pada setiap menitnya dapat dilihat pada Tabel 2.

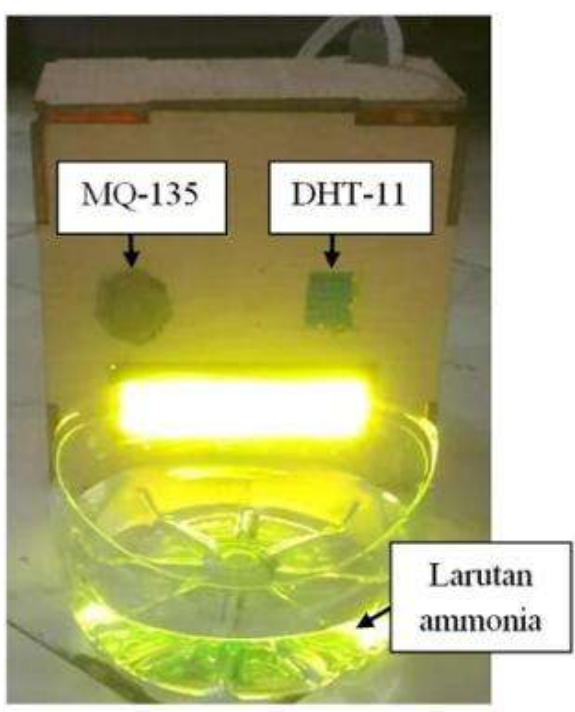

Gambar 8. Susunan Eksperimen pada Lingkungan Luar Ruangan

Tabel 2. Hasil Pengujian Sistem Monitoring yang dihasilkan pada Lingkungan Luar Ruangan

\begin{tabular}{|c|c|c|c|}
\hline Menit ke- & Kadar Gas Ammonia (ppm) & Suhu ( ${ }^{\circ} C$ ) & Waktu Pengujian (WIB) \\
\hline 1 & 3,73 & 30,60 & $15: 27: 00$ \\
\hline 2 & 3,66 & 30,40 & $15: 28: 00$ \\
\hline 3 & 2,41 & 30,40 & $15: 29: 00$ \\
\hline 4 & 3,53 & 30,40 & $15: 30: 00$ \\
\hline 5 & 3,22 & 30,60 & $15: 31: 00$ \\
\hline 6 & 2,39 & 30,70 & $15: 32: 00$ \\
\hline 7 & 2,93 & 30,40 & $15: 33: 00$ \\
\hline 8 & 2,62 & 30,40 & $15: 34: 00$ \\
\hline 9 & 2,03 & 30,40 & $15: 35: 00$ \\
\hline 10 & 1,87 & 30,40 & $15: 36: 00$ \\
\hline 11 & 2,67 & 30,40 & $15: 37: 00$ \\
\hline 12 & 2,39 & 30,40 & $15: 38: 00$ \\
\hline 13 & 2,18 & 30,70 & $15: 39: 00$ \\
\hline 14 & 1,81 & 30,30 & $15: 40: 00$ \\
\hline 15 & 1,60 & 30,30 & $15: 41: 00$ \\
\hline 16 & 2,33 & 30,70 & $15: 42: 00$ \\
\hline
\end{tabular}


Data sampel pengujian dalam waktu selama 16 menit ini dinilai sudah cukup mewakili kinerja sistem yang dikembangkan ketika dioperasikan dalam waktu yang lama. Hasil pengukuran pada Tabel 2 menunjukkan sistem monitoring mampu mengukur suhu lingkungan aktual yaitu antara $30,30-30,70{ }^{\circ} \mathrm{C}$ dan kadar gas amonia yaitu antara $1,60-3,73 \mathrm{ppm}$ dengan stabil tanpa ada perubahan hasil pengukuran yang drastis. Pada tabel dapat dilihat adanya perbedaan hasil pengukuran gas amonia, namun selisihnya sedikit yaitu dibawah 2,2 ppm.

\subsection{Pengujian pada Lingkungan Kandang Ayam}

Pengujian terakhir yang dilakukan adalah pengujian pada lingkungan kandang ayam yang sesungguhnya. Lingkungan kandang ayam yang dipilih adalah kandang ayam peternakan rakyat yang biasanya mempunyai skala usaha mikro atau sangat kecil dan belum menggunakan fasilitas modern seperti kandang ayam skala menengah dan besar. Kandang ayam yang dipakai dalam eksperimen adalah model kandang terbuka dimana kandang mempunyai atap namun dindingnya terbuat dari bilah bambu yang memungkinkan udara bisa keluar masuk dalam kandang. Susunan eksperimen pengujian sistem monitoring ini dapat dilihat pada Gambar 9. Pada eksperimen yang dilakukan, posisi kotak sistem monitoring diletakkan menghadap ke atas dan menghadap ke samping untuk mengetahui perbedaan kinerja keduanya. Hasil pengukuran menunjukkan dua posisi ini mempunyai hasil pengukuran yang sama. Untuk melihat kinerjanya sepanjang waktu, pengujian dilakukan selama dua hari pada rentang waktu yang berbeda yaitu pada siang hari (untuk hari pertama) dan pagi hari (untuk hari kedua). Data hasil pengukuran dapat dilihat langsung pada penampil LCD seperti yang ditunjukkan pada Gambar 9 dan juga menggunakan aplikasi Telegram dan Blynk pada smartphone Android.
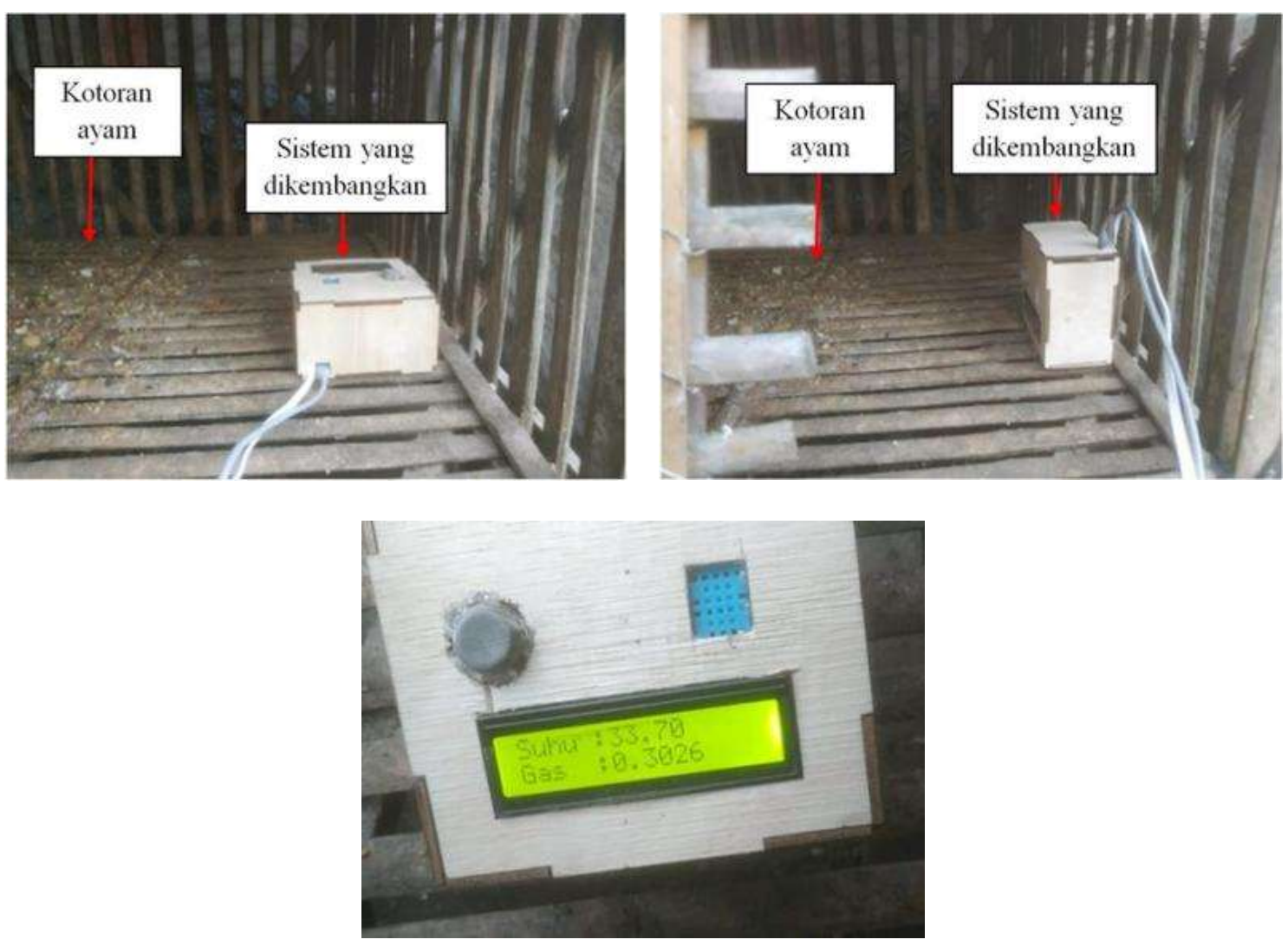

Gambar 9. Susunan Pengujian pada Lingkungan Kandang Ayam Aktual 
Data hasil eksperimen yang ditampilkan pada Tabel 3 menunjukkan sistem mampu mengukur suhu aktual lingkungan kandang yaitu antara 33.40-33,60 ${ }^{\circ} \mathrm{C}$ dan kadar gas amonia aktual yaitu antara 0,36-1,66 ppm dengan stabil tanpa adanya perubahan yang drastis dan tiba-tiba. Sistem monitoring yang dikembangkan ini juga dilengkapi dengan sistem notifikasi yaitu sistem akan memberikan notifikasi melalui aplikasi Telegram apabila kadar gas amonia melebihi kadar tertentu yang besarnya dapat diubah-ubah sesuai dengan kriteria yang diperlukan. Pada artikel ini, untuk eksperimen, batas kadar gas amonia untuk dapat mengaktifkan notifikasi adalah 100 ppm.

Hasil pengujian pada skala laboratorium dan pada lingkungan kandang ayam aktual menunjukkan bahwa sistem monitoring yang dihasilkan dalam artikel ini mempunyai kinerja yang stabil sehingga berpotensi untuk digunakan dalam peternakan rakyat. Ketika digunakan, sistem monitoring akan menghasilkan data suhu dan kadar gas amonia sekitar kandang sehingga peternak dapat mengambil keputusan untuk melakukan tindakan korektif seperti pembersihan kotoran ayam pada kandang, perbaikan ventilasi kandang atau tindakan lain. Selain itu, data kadar gas amonia pada lingkungan sekitar kandang juga bermanfaat bagi peternak maupun orang yang bekerja pada peternakan itu. Udara dengan kadar amonia tinggi yang dihirup setiap hari dapat berpengaruh buruk bagi kesehatan manusia.

Table 3. Hasil Pengujian Sistem Monitoring pada Lingkungan Kandang Aktual

\begin{tabular}{|c|c|c|c|c|}
\hline Hari Ke- & $\begin{array}{c}\text { Menit } \\
\text { ke- }\end{array}$ & $\begin{array}{c}\text { Kadar Gas } \\
\text { Ammonia (ppm) }\end{array}$ & Suhu ( $\left.{ }^{\circ} \mathrm{C}\right)$ & $\begin{array}{c}\text { Waktu Pengujian } \\
\text { (WIB) }\end{array}$ \\
\hline \multirow{6}{*}{} & 1 & 0,36 & 33,60 & $15: 59: 00$ \\
\cline { 2 - 5 } & 2 & 0,36 & 33,50 & $16: 01: 00$ \\
\cline { 2 - 5 } & 3 & 0,35 & 33,50 & $16: 02: 00$ \\
\cline { 2 - 5 } & 4 & 0,36 & 33,60 & $16: 03: 00$ \\
\cline { 2 - 5 } & 5 & 0,37 & 33,40 & $16: 04: 00$ \\
\cline { 2 - 5 } & 6 & 0,36 & 33,60 & $16: 05: 00$ \\
\cline { 2 - 5 } & 7 & 0,37 & 33,60 & $16: 06: 00$ \\
\cline { 2 - 5 } & 8 & 0,36 & 33,40 & $16: 07: 00$ \\
\hline \multirow{6}{*}{2} & 9 & 0,36 & 33,60 & $16: 08: 00$ \\
\cline { 2 - 5 } & 10 & 0,36 & 33,60 & $16: 09: 00$ \\
\cline { 2 - 5 } & 1 & 1,36 & 33,60 & $10: 20: 00$ \\
\cline { 2 - 5 } & 2 & 1,66 & 33,50 & $10: 21: 00$ \\
\cline { 2 - 5 } & 3 & 1,60 & 33,50 & $10: 23: 00$ \\
\cline { 2 - 5 } & 4 & 1,36 & 33,60 & $10: 24: 00$ \\
\cline { 2 - 5 } & 5 & 1,30 & 33,40 & $10: 25: 00$ \\
\cline { 2 - 5 } & 6 & 1,52 & 33,60 & $10: 27: 00$ \\
\cline { 2 - 5 } & 7 & 1,40 & 33,60 & $10: 28: 00$ \\
\cline { 2 - 5 } & 8 & 1,55 & 33,40 & $10: 29: 00$ \\
\cline { 2 - 5 } & 9 & 1,51 & 33,60 & \\
\hline
\end{tabular}

Meski berpotensi tinggi untuk diimplementasikan pada peternakan ayam rakyat skala kecil, sistem yang dihasilkan ini masih memerlukan uji validitas dan pengujian standar di badan metrologi untuk memastikan bahwa sistem monitoring mempunyai hasil pengukuran yang valid dan memenuhi syarat untuk digunakan. 


\section{KESIMPULAN}

Kesimpulan yang dapat diambil dari hasil penelitian ini adalah sebagai berikut. Sebuah model sistem elektronis untuk pemantauan suhu dan kadar gas amonia yang dapat diimplementasikan pada kandang ayam sudah berhasil dikembangkan dengan menggunakan komponen utama yang ada di pasaran meliputi sensor MQ-135, sensor DHT-11, mikrokontroler Arduino Pro Mini dan mikrokontroler Wemos D1. Hasil pengujian pada skala laboratorium (dalam lingkungan dalam ruangan dan luar ruangan) selama 30 menit dan pengujian pada lingkungan kandang ayam aktual selama 2 hari masing-masing 10 menit pengukuran dapat diketahui bahwa sistem yang dihasilkan mampu mengolah data dari sensor yang digunakan dan menampilkan data lingkungan yang saat pengujian pada rentang yaitu untuk suhu adalah $29-33,60{ }^{\circ} \mathrm{C}$ dan untuk gas amonia adalah 0,36-197,56 ppm pada penampil LCD dan pada smartphone Android dengan menggunakan aplikasi Telegram dan Blynk. Data pengujian menunjukkan sistem bekerja dengan stabil tanpa ada perubahan pengukuran yang sifatnya drastis dan tiba-tiba. Berdasarkan hasil pengujian ini, dapat dililihat bahwa sistem monitoring yang dikembangkan mempunyai potensi yang baik untuk diuji pada skala yang lebih luas dan dilakukan uji standar pengukuran pada lembaga

pemerintah seperti badan metrologi sehingga memenuhi syarat untuk diterapkan pada kandang ayam peternakan rakyat skala mikro dan kecil.

\section{DAFTAR RUJUKAN}

Alimuddin, Seminar, K. B., Subrata, I. D. M., Nomura, N., \& Sumiati. (2012). Temperature control system in closed house for broilers based on anfis. Telkomnika, 10(1), 75-82.

Arifin, M. N., Ichsan, M. H. H., \& Akbar, S. R. (2018). Monitoring Kadar Gas Berbahaya Pada Kandang Ayam Dengan Menggunakan Protokol HTTP Dan ESP8266. Jurnal Pengembangan Teknologi Informasi dan Ilmu Komputer, 2(11), 4600-4606

Budiarto, R., Gunawan, N. K., \& Nugroho, B. A. (2020). Smart chicken farming: minitoring system for temperature, ammonia levels, feed in chicken farms. IOP Conference Series: Materials and Engineering, 852(2020), 1-6

Budianto, E. W. S., Ramadiani, \& Kridalaksana, A. H. (2017). Prototipe sistem kendali pengaturan suhu dan kelembaban kandang ayam boiler berbasis mikrokontroler ATMega328. Prosiding Seminar Nasional Ilmu Komputer dan Teknologi Informasi, (pp. 70-73).

Corkery, G., Ward, S., Kenny, C., \& Hemmingway, P. (2013). Incorporating Smart Sensing Technologies into the Poultry Industry. Journal of World's Poultry Research, 3(4), 106-128.

Esnaola-Gonzales, I., Gomez-Omella, M., Ferreiro, S., Fernandez, I., Lazaro, I., \& Garcia, E. (2020). An IoT platform towards the enhancement of poultry production chains. Sensors 2020, 20, 1-20. 
Heriawan, R., Suciati, S. W. \& Supriyanto, A. (2013). Alat Pengontrol Emisi Gas Amonia (NH3) di Peternakan Ayam Berbasis Mikrokontroler ATMega 8535 Menggunakan Sensor Gas MQ-137. JURNAL Teori dan Aplikasi Fisika, 1(1), 69-73.

Hidayanti, F. (2020). Implementation of Blynk internet of things platform for benzene gas monitoring system on density laboratory. International Journal of Innovative Technology and Exploring Engineering (IJITEE), 944), 1090 - 1094.

Kilic, I. \& Yaslioglu, E. (2014). Ammonia and carbon dioxide concentrations in a layer house. Asian Australasian Journal of Animal Sicence, 27(8), 1211-1218.

Kurniawan, M. I., Sunarya, U., Tulloh, R. (2018). Internet of Things : Sistem Keamanan Rumah berbasis Raspberry Pi dan Telegram Messenger. ELKOMIKA, 6(1), 1-15.

Logan, M., Safi, M., Lens, P., \& Visvanathan, C. (2019). Investigating the performance of internet of things based anaerobic digestion of food waste. Process Safety and Environmental Protection, 1272019), 277-287.

Maliselo, P. S., \& Nkonde, G. K. (2015). Ammonia production in poultry houses and its effect on the growth of Gallus Gallus Domestica (broiler chickens): a case study of a small scale poultry house in riverside, Kitwe, Zambia. International Journal of Scientific \& Technology Research, 4(4), 141-145.

Muta'affif, M. F., Mujtahid, M., El Bari, B., Evita, M. \& Djamal, M. (2017). Sistem Kendali Peternakan Jarak Jauh Berbasis Internet of Things (IoT). Prosiding SKF 2017, November 2017, (pp. 98-102).

Putra, C. G. N., Maulana, R., \& Fitriyah, H. (2018). Otomasi Kandang Dalam Rangka Meminimalisir Heat Stress Pada Ayam Broiler Dengan Metode Naive Bayes. Jurnal Pengembangan Teknologi Informasi dan IImu Komputer, 2(1), 387-394.

Renata, R., Sarjana, T. A., \& Kismiati, S. (2018). Pengaruh zonasi dalam kandang closed house terhadap kadar amonia dan dampaknya pada kualitas daging broiler di musim penghujan. Jurnal IImu-IImu Peternakan 28(3), 183 - 191

Santoso, H. B., Prajogo, S., \& Mursid, S. P. (2018). Pengembangan Sistem Pemantauan Konsumsi Energi Rumah Tangga Berbasis Internet of Things (IoT). ELKOMIKA, 6(3), 357-366.

Supriyono, H. \& Hadi, A. N. (2017). Designing a wheeled robot model for flammable gas leakage tracking. Proceedings of the second International Conference on Informatics and Computing, Jayapura, 1-2 November 2017, (pp. 1-6). 
Triawan, A., Sudrajat, D., \& Anggraeni. (2013). Performa ayam broiler yang diberi ransum mengandung neraca kation Anion ransum yang berbeda. Jurnal Pertanian, 4(2), 7381.

Tamzil, M. H. (2014). Stres Panas pada Unggas: Metabolisme, Akibat dan Upaya Penanggulangannya. WARTAZOA, 24(2), 57-66.

Vishesh, S., Srinath, M., Nakul, R. B., Adithya, V., Kumar, P. P., \& Swathi, S. (2016). Ammonia gas leakage monitoring system using MQ-137 sensors, IoT and framing suitable reflexive actions. International Journal of Advanced Research in Computer and Communication Enginering, 5(11), 601-604. 